\title{
BENZENE PURITY IN RADIOCARBON DATING SAMPLES
}

\author{
ROY SWITSUR \\ Godwin Laboratory, Cambridge University, Cambridge, England CB2 3RS \\ and \\ JOHN S WATERHOUSE \\ Cambridgeshire College of Arts and Technology, East Road, Cambridge
}

\begin{abstract}
Gas chromatographic analysis of the benzene obtained for radiocarbon dating revealed only very low levels ( $<200 \mathrm{ppm}$ in total) of impurities, most of which were alkylbenzenes. Traces of acetone and phenol were also found. These impurities, at such low levels are thought unlikely to affect counting efficiency.
\end{abstract}

\section{INTRODUCTION}

Cyclotrimerziation of acetylene to produce benzene for use in liquid scintillation spectrometry is now a common procedure in many radiocarbon dating laboratories. The technique employs commercially available cracking catalysts activated by chromium, vanadium or molybdenum in high valency state. It is important that the benzene synthesized should be of a sufficiently high purity that quenching is minimal so that the age determinations are consistent. Several previous studies of benzene purity have been made (eg, Coleman et al, 1973; Polach, Gower \& Frazer 1973; Tamers, 1975). These authors all report high yield of benzene but with side products in small quantities including acetone and methanol. It is important that the purity of the benzene synthesized in dating laboratories should be kept under review.

\section{AIMS}

The study here outlined was to investigate the level of impurities in benzene synthesized using a chromium-activated cracking catalyst (KCPerlkator D1) and to check reports of non-catalytic redox reactions leading to the incorporation of oxygen and the formation of acetone and possibly other oxygen-containing products.

\section{METHODS AND RESULTS}

Specimens of benzene for analysis were obtained from separate ${ }^{14} \mathrm{C}$ samples, which included peat, soil, marine silt and bone collagen. In each case fresh catalyst was used to prepare the specimens of benzene. The catalyst was heated for several hours in air and dried thoroughly by heating in vacuum before use. The isolated yield of benzene in each of the runs was $90-100 \%$. Analyses of the benzene were carried out on a Hewlett-Packard 5890 gas chromatograph linked to a mass spectrometer detector. A methyl silicone capillary column (length $12 \mathrm{~m}$, id $0.2 \mathrm{~mm}$ ) was used with a temperature program of $40^{\circ}-100^{\circ} \mathrm{C}$ in $5 \mathrm{~min}$, a split ratio of 7.5 and a carrier gas (helium) flow rate of $0.88 \mathrm{ml} / \mathrm{min}$. The components were identified from their mass spectra and by co-injection with authentic samples. The amount of each component was determined using a series of separately prepared standard solutions together with values of chromatographic peak areas. The analytical results showed that all the samples consisted of benzene in a high state of purity $(>99.9 \%)$. Each specimen of benzene was found to contain 


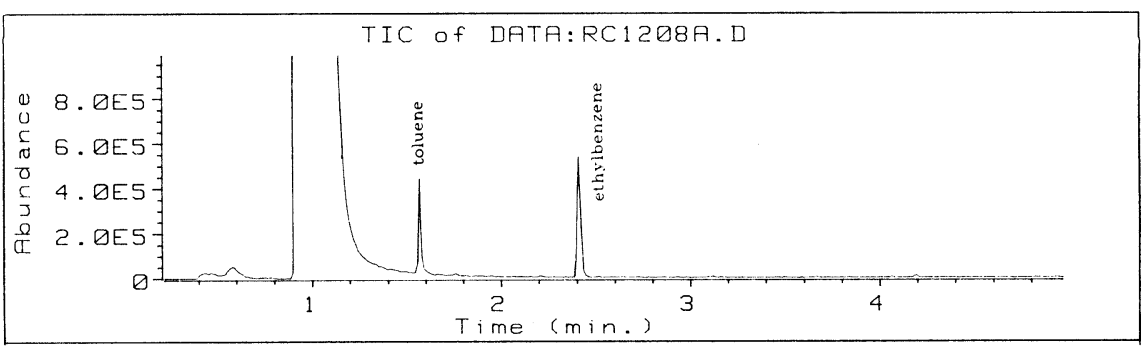

Fig 1. Total ion chromatograph of sample RC 1208

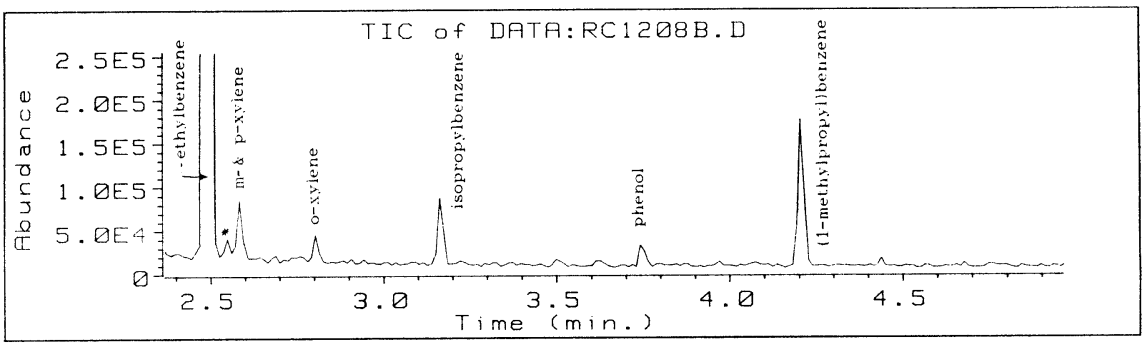

* Impurity from column

Fig 2. Total ion chromatograph of sample RC 1208 at high sensitivity

TABLE 1

Impurities in benzene specimen $\mathrm{RC} 1208$

\begin{tabular}{lccc}
\hline Component & $\begin{array}{c}\text { Retention } \\
\text { time/min }\end{array}$ & $\begin{array}{c}\text { Quantity } \\
\text { Relative abundance }\end{array}$ & ppm \\
\hline Benzene & 0.997 & 100 & - \\
Ethylbenzene & 2.495 & $8.6 \times 10^{-3}$ & 86 \\
Toluene & 1.566 & $6.0 \times 10^{-3}$ & 60 \\
Acetone & 0.575 & $7.2 \times 10^{-4}$ & 7.2 \\
(1-methylpropyl)benzene & 4.203 & $3.8 \times 10^{-4}$ & 3.8 \\
Isopropylbenzene & 3.163 & $1.6 \times 10^{-4}$ & 1.6 \\
$m$-Xylene \& $p$-Xylene & 2.582 & $1.4 \times 10^{-4}$ & 1.4 \\
$o$-Xylene & 2.802 & $6.3 \times 10^{-5}$ & 0.6 \\
Phenol & 3.742 & $5.2 \times 10^{-5}$ & 0.5 \\
\hline
\end{tabular}

${ }^{*} \mathrm{~m} \& \mathrm{p}$ xylenes could not be separated effectively on the column used 
the same nine impurities: - ethylbenzene; toluene; acetone; (1-methylpropyl)benzene; isopropylbenzene; ortho, meta and para xylenes and phenol. The concentrations of these impurities varied haphazardly between specimens up to $30 \%$ or more. The reasons for these variations is unknown, but considering that the benzene was obtained from different types of ${ }^{14} \mathrm{C}$ samples, it is perhaps not too surprising. Chromatographs for sample $\mathrm{RC1208,} \mathrm{which} \mathrm{was} \mathrm{considered} \mathrm{to} \mathrm{be} \mathrm{a} \mathrm{typical} \mathrm{sample,} \mathrm{are} \mathrm{shown} \mathrm{in} \mathrm{Figures}$ 1 and 2 with corresponding analytical data in Table 1 . The amount of ethylbenzene in $\mathrm{RC} 1208$ was towards the top of the range; values from other specimens were generally ca $60-70 \mathrm{ppm}$. For comparison, levels of impurities in scintillator-grade benzene (ex BDH) are shown in Table 2.

TABLE 2

Impurities in scintillator-grade benzene

\begin{tabular}{lc}
\hline & $\begin{array}{c}\text { Concentration } \\
\text { ppm }\end{array}$ \\
\hline Toluene & 6.0 \\
Ethylbenzene & 2.8 \\
$m+p$ xylene & 3.6 \\
Methlylcyclohexane & 3.0 \\
Methylcyclopentane & 3.0 \\
Chloroform & 0.6 \\
\hline
\end{tabular}

\section{DISCUSSION}

The results clearly demonstrate the high level of purity of the benzene. Most of the side products are alkylbenzenes, with toluene and ethylbenzene as the major contributors. Similar findings were obtained by Polach (1973) using the Noakes vanadium catalyst. The origin of these alkylbenzenes is uncertain. Shirakawa and Ikeda (1974) reported the formation of small amounts of ethylbenzene during the cyclotrimerization of acetylene on a tris(acetylacetonato)titanium(iii)-diethylaluminium chloride catalyst. They argued that the ethyl group was derived from the catalyst. With our catalyst, such an explanation is not possible. It may be that the formation, in our system, of both ethylbenzene and (1-methylpropyl)benzene involves hydrogen transfer reactions from other acetylene molecules. Such loss of hydrogen from acetylene has been reported by Tamers (1975). Alternatively, residual traces of water in the catalyst could be involved, despite the latter being carefully heated in vacuo before use. It is very difficult, if not impossible in practice to remove the last vestiges of water from so porous a material. The presence of toluene, xylenes and isopropylbenzene could be explained by the presence of propylene in the acetylene. Further work is needed to clarify these points.

The low levels of acetone and phenol indicate some incorporation of oxygen from the catalyst or from traces of water into the non-volatile products. Both this and reactions involving hydrogen transfer suggest that some non-catalytic redox reactions take place on the catalyst. That such reactions 
occur is confirmed by the color change of the catalyst during reaction (typically from yellow to greenish gray to brown). The possible formation of non-volatile products, which might also contain oxygen, such as polymers (Belluomini et al, 1978) and acetates and carbonates (Tamers, 1975), was not investigated in this study; however, the non-quantitative yields of benzene from some of the runs suggest that non-volatile products are indeed formed. Table 2 shows that the level of impurities in scintillator-grade benzene are considerably lower than in that synthesized from the ${ }^{14} \mathrm{C}$ samples. The type of impurities, however, are similar, with the exception of chloroform. This is an unexpected contaminant, but the concentration is very low and it is most unlikely to affect the counting efficiency.

Although several impurity compounds are present in the benzene synthesized from ${ }^{14} \mathrm{C}$ samples, their levels are low and it is likely that they present no problems in dating. However, further investigations are planned to attempt to account for the formation of these compounds and to discover at what concentrations some or all of them might become significant in age determinations.

\section{REFERENCES}

Belluomini, G, Delfino, A, Manfra, L and Petrone, V, 1978, Benzene synthesis for radiocarbon dating and a study of the catalyst used for acetylene trimerization: Internatl Jour Appl Radiation Isotopes, v 29, p 453-459.

Coleman, D D, Liu, C L, Dickerson, D R and Frost, R R, 1973, Improvement in trimerisation of acetylene to benzene for radiocarbon dating with a commercially available vanadium oxide catalyst, in Rafter, T A and Grant-Taylor, T, eds, Internatl conf on ${ }^{14} \mathrm{C}$ dating, 8th, Proc: Wellington, New Zealand, Royal Soc New Zealand, v 1, p 158-170.

Polach, H A, Gower, J and Frazer, I, 1973, Synthesis of high purity benzene for radiocarbon dating, in Rafter, $\mathrm{T} A$ and Grant-Taylor, $\mathrm{T}$, eds, Internatl conf on ${ }^{14} \mathrm{C}$ dating, 8th, Proc: Wellington, New Zealand, Royal Soc New Zealand, v 1, p 145-157.

Shirakawa, $\mathbf{H}$ and Ikeda, S, 1974, Cyclotrimerization of acetylene by the tris(acetylacetonato)titanium (iii)-diethylaluminium chloride system: Jour Polymer Sci Polymer Chem, v 12, p 929-937.

Tamers, M A, 1975, Chemical yield optimisation of the benzene synthesis for radiocarbon dating: Internatl Jour Appl Radiation Isotopes, v 26, p 676-682. 